\title{
Optimal Control of a PEM Fuel Cell for the Inputs Minimization
}

\author{
José de Jesús Rubio ${ }^{1}$ and Adrian Gustavo Bravo² \\ ${ }^{1}$ Sección de Estudios de Posgrado e Investigación, ESIME Azcapotzalco, Instituto Politécnico Nacional, \\ Avenida de las Granjas 682, Colonia Santa Catarina, 02250 México D.F., Mexico \\ ${ }^{2}$ Centro de Investigación e Inovación Tecnológica, Instituto Politécnico Nacional, Cerrada Cecaty $s / n$, \\ Colonia Santa Catarina, 02250 México D.F., Mexico \\ Correspondence should be addressed to José de Jesús Rubio; jrubioa@ipn.mx
}

Received 26 December 2013; Revised 5 February 2014; Accepted 10 February 2014; Published 19 March 2014

Academic Editor: Mingcong Deng

Copyright (C) 2014 J. J. Rubio and A. G. Bravo. This is an open access article distributed under the Creative Commons Attribution License, which permits unrestricted use, distribution, and reproduction in any medium, provided the original work is properly cited.

The trajectory tracking problem of a proton exchange membrane (PEM) fuel cell is considered. To solve this problem, an optimal controller is proposed. The optimal technique has the objective that the system states should reach the desired trajectories while the inputs are minimized. The proposed controller uses the Hamilton-Jacobi-Bellman method where its Riccati equation is considered as an adaptive function. The effectiveness of the proposed technique is verified by two simulations.

\section{Introduction}

A fuel cell is an electrochemical device that converts chemical energy stored in fuel into electricity. PEM fuel cells have seen a great amount of development in recent years. Fuel cell integrated to renewable energy systems offers many socioeconomic benefits. Understanding the behavior of PEM fuel cell stacks at varying loads is vital for the control of the efficiency.

There is some research about controllers applied to PEM fuel cells. In [1], a nonlinear-control strategy for PEM fuel cells by using the exact linearization approach is presented. In [2], a nonlinear controller is designed based on the proposed model to prolong the stack life of the PEM fuel cells. In [3], a higher-order sliding-mode supertwisting algorithm has been designed to control a motor that drives a compressor designed to feed the $33 \mathrm{~kW}$ fuel cell with air. Therefore, the controllers design to improve the performance of the PEM fuel cells would be of great importance; and none of the above researches introduces an optimal controller.

There are some works about control. Fuzzy controls for nonlinear systems are proposed in $[4,5]$. In [6-10], robust controls of nonlinear systems are introduced. The bangbang optimal control problem associated with hydraulic systems is addressed in [11]. The research of [12] deals with multiobjective optimization techniques for a class of hybrid optimal control problems in mechanical systems. In [13, 14], optimal controls of robotics arms are considered. None of the above studies is applied to PEM fuel cell; thereby, in this study, an optimal controller of a PEM fuel cell is introduced. The proposed controller uses the solution of the Hamilton-Jacobi-Bellman equations where its Riccati equation is considered as an adaptive function; that is, in other papers, the Riccati equation is solved in an inverse form using the final conditions, while in this paper, the Riccati equation is solved in a forward form using the initial conditions.

This paper is organized as follows. Section 2 presents the modified PEM fuel cell dynamic model which includes an external load. In Section 3, the optimal control of the PEM fuel cell is designed. In Section 4, the optimal method and dual proportional-derivative technique are compared by two simulations. Section 5 presents conclusions and suggests future research directions.

\section{Modified PEM Fuel Cell Dynamic Model}

In this section, the PEM fuel cell dynamic model of [1] is described; it will be used in the following section for the control design. Furthermore, the PEM fuel cell dynamic model is modified to include an external load which makes it more approximated with the real process. 
The following assumptions are applied to construct the simplified dynamic model for the PEM fuel cell [1]. (1) The gases are ideal. (2) The water management and the humidification of system are not considered in this paper. (3) The oxygen flow rate is determined by the hydrogen-oxygen flow ratio from the reformer. (4) The stack temperature is regulated $80^{\circ} \mathrm{C}$ by using an independent cooling system. (5) The Nernst equation is applied.

2.1. Modified PEM Fuel Cell Output Voltage Equation. The output stack voltage $V$ defined as a function of the stack current, reactant partial pressures, fuel cell temperature, and membrane humidity, is as follows $[1,2,15,16]$ :

$$
V=E-V_{\text {activation }}-V_{\text {ohmic }}-V_{\text {concentration }} \text {, }
$$

where $E=N\left(E^{o}+(R T / 2 F) \ln \left\{p \mathrm{H}_{2}\left(p \mathrm{O}_{2} / P_{\text {std }}\right)^{1 / 2} / p \mathrm{H}_{2} \mathrm{O}_{C}\right\}\right)$ is the thermodynamic potential of the cell or reversible voltage based on the Nernst equation, $N$ is the number of cells in the stack, $E^{o}$ is the cell-open-circuit voltage, $T$ is the operating temperature, $p \mathrm{H}_{2}, p \mathrm{O}_{2}$, and $p \mathrm{H}_{2} \mathrm{O}_{C}$ are the partial pressures of hydrogen, oxygen, and water gas inside the cell, respectively, $R$ is the gas constant $\left(8.3144 \mathrm{~J} / \mathrm{mol}^{0} \mathrm{~K}\right)$, $F$ is the Faraday constant $(96439 \mathrm{C} / \mathrm{mol}), P_{\text {std }}$ is the standard pressure $(101325 \mathrm{~Pa})$, and $V_{\text {activation }}$ is the voltage loss due to the reactions of the electrodes surface. $V_{\text {ohmic }}$ is the ohmic voltage drop from the resistances of proton flow in the electrolyte. $V_{\text {concentration }}$ is the voltage loss from the reduction of concentration gases or the transport of a mass of oxygen and hydrogen. The equations are given as follows $[2,15,16]$ :

$$
\begin{gathered}
V_{\text {activation }}=N \frac{R T}{2 \alpha F} \ln \left(\frac{i+i_{n}}{i_{0}}\right)=N C \ln \left(\frac{i+i_{n}}{i_{0}}\right), \\
V_{\text {ohmic }}=N r i, \\
V_{\text {concentration }}=N m e^{n i},
\end{gathered}
$$

where $C=R T / 2 \alpha F, i$ is the output current density, $i_{n}$ is the internal current density related to the internal current losses, $i_{0}$ is the exchange current density related to activation losses, $\alpha$ is a charge transfer coefficient, $r$ is the area-specific resistance related to resistive losses, and $m$ and $n$ are constants in the mass transfer voltage.

In this study, the output stack voltage $V$ of (1) is modified with the consideration of an external load as can be seen in Figure 1.

It is described as follows:

$$
V=E-V_{\text {activation }}-V_{\text {ohmic }}-V_{\text {concentration }}-V_{\text {load }} \text {, }
$$

where $V_{\text {activation }}, V_{\text {ohmic }}$, and $V_{\text {concentration }}$ are defined in (2), (3), and (4), respectively, $V_{\text {load }}=R_{l} i$ is the load voltage, $i$ is the output current density, and $R_{l}$ is the load resistance.

2.2. State Equations. The partial pressures of hydrogen, oxygen, and water on the cathode side are defined as the state variables of the system, and the relationship between the inlet and the outlet gases is as follows [1]:

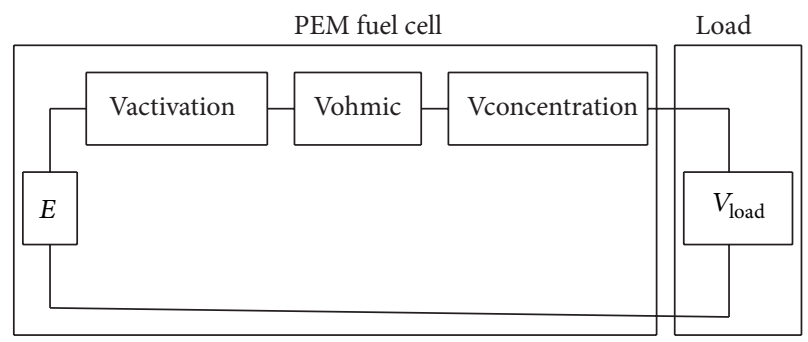

FIgURE 1: PEM fuel cell.

Anode:

$$
\mathrm{H}_{2, \text { in }}+\mathrm{H}_{2} \mathrm{O}_{A, \text { in }}=\mathrm{H}_{2, \text { out }}+\mathrm{H}_{2} \mathrm{O}_{A, \text { out }} \text {. }
$$

Cathode:

$$
\mathrm{N}_{2 \text {,in }}+\mathrm{O}_{2, \text { in }}+\mathrm{H}_{2} \mathrm{O}_{\text {, in }}=\mathrm{N}_{2 \text {, out }}+\mathrm{O}_{2 \text {, out }}+\mathrm{H}_{2} \mathrm{O}_{C \text {, out }} \text {. }
$$

From the ideal gas law, it is known that the partial pressure of each gas is proportional to the amount of gas in the cell, to which there are three relevant contributions depending on the gas inlet flow rate, gas consumption, and gas outlet flow rate. Thus, the state equations are [1]

$$
\begin{aligned}
& \frac{d p \mathrm{H}_{2}}{d t}=\frac{R T}{V_{A}}\left[\mathrm{H}_{2, \text { in }}-2 K_{r} A_{c} i-\left(\mathrm{H}_{2, \text { in }}-2 K_{r} A_{c} i\right) \frac{p \mathrm{H}_{2}}{p_{\mathrm{op}}}\right], \\
& \frac{d p \mathrm{O}_{2}}{d t}=\frac{R T}{V_{C}}\left[\mathrm{O}_{2, \text { in }}-K_{r} A_{c} i-\left(\mathrm{O}_{2, \text { in }}-K_{r} A_{c} i\right) \frac{p \mathrm{O}_{2}}{p_{\mathrm{op}}}\right], \\
& \frac{d p \mathrm{H}_{2} \mathrm{O}_{\mathrm{C}}}{d t} \\
& =\frac{R T}{V_{C}}\left[\mathrm{H}_{2} \mathrm{O}_{C, \text { in }}+2 K_{r} A_{c} i-\left(\mathrm{O}_{2, \text { in }}+2 K_{r} A_{c} i\right) \frac{p \mathrm{H}_{2} \mathrm{O}_{\mathrm{C}}}{p_{\mathrm{op}}}\right],
\end{aligned}
$$

where $K_{r}=N / 4 F, A_{c}$ is the cell active area, $i$ is defined in (2)(4), $P_{\text {op }}$ is the operating pressure, $V_{A}$ is the anode volume, $V_{C}$ is the cathode volume, $R$ and $T$ are defined in (1), $\mathrm{H}_{2, \text { in }}, \mathrm{O}_{2, \text { in }}$, and $\mathrm{H}_{2} \mathrm{O}_{C \text {,in }}$ are the inlet flow rates of the hydrogen, oxygen, and water of the cathode, respectively, and $\mathrm{pH}_{2}, \mathrm{pO}_{2}$, and $\mathrm{pH}_{2} \mathrm{O}_{\mathrm{C}}$ are the partial pressures of hydrogen, oxygen, and water inside the cell, respectively.

2.3. The Final System. The water input $\mathrm{H}_{2} \mathrm{O}_{C \text {,in }}$ is not considered in the state equations because it is not an input of the process in most of the applications. Defining the states as $x_{1}=p \mathrm{H}_{2}, x_{2}=p \mathrm{O}_{2}$, and $x_{3}=p \mathrm{H}_{2} \mathrm{O}_{C}$, the inputs as 
$u_{1}=\mathrm{H}_{2, \text { in }}, u_{2}=\mathrm{O}_{2 \text {,in }}$, and $u_{3}=i$ and the output as $y=V$ give the following state space system:

$$
\begin{gathered}
\dot{x}_{1}=\frac{R T}{V_{A}}\left(-\frac{u_{1}}{p_{\mathrm{op}}}+2 K_{r} A_{c} \frac{u_{3}}{p_{\mathrm{op}}}\right) x_{1}+\frac{R T}{V_{A}} u_{1}-\frac{R T}{V_{A}} 2 K_{r} A_{c} u_{3}, \\
\dot{x}_{2}=\frac{R T}{V_{C}}\left(-\frac{u_{2}}{p_{\mathrm{op}}}+K_{r} A_{c} \frac{u_{3}}{p_{\mathrm{op}}}\right) x_{2}+\frac{R T}{V_{C}} u_{2}-\frac{R T}{V_{C}} K_{r} A_{c} u_{3}, \\
\dot{x}_{3}=\frac{R T}{V_{C}}\left(-\frac{u_{2}}{p_{\mathrm{op}}}-2 K_{r} A_{c} \frac{u_{3}}{p_{\mathrm{op}}}\right) x_{3}+\frac{R T}{V_{C}} 2 K_{r} A_{c} u_{3}, \\
y=N\left(E^{o}+\frac{R T}{2 F} \ln \left\{\frac{x_{1}\left(x_{2} / P_{\mathrm{std}}\right)^{1 / 2}}{x_{3}}\right\}\right) \\
-N C \ln \left(\frac{u_{3}+i_{n}}{i_{0}}\right)-N r u_{3}-N m e^{n u_{3}}-R_{l} u_{3} .
\end{gathered}
$$

The nonlinear system (9) is rewritten as follows:

$$
\begin{gathered}
\dot{x}=A x+B u=f(x, u), \\
y=q(x, u),
\end{gathered}
$$

where $A=\left[\begin{array}{ccc}a_{1} & 0 & 0 \\ 0 & a_{2} & 0 \\ 0 & 0 & a_{3}\end{array}\right] \in \mathfrak{R}^{3 \times 3}, a_{1}=\left(R T / V_{A}\right)\left(-u_{1} / p_{\text {op }}+\right.$ $\left.2 K_{r} A_{c}\left(u_{3} / p_{\text {op }}\right)\right), a_{2}=\left(R T / V_{C}\right)\left(-u_{2} / p_{\text {op }}+K_{r} A_{c}\left(u_{3} / p_{\text {op }}\right)\right)$, $a_{3}=\left(R T / V_{C}\right)\left(-u_{2} / p_{\text {op }}-2 K_{r} A_{c}\left(u_{3} / p_{\text {op }}\right)\right), B=\left[\begin{array}{ccc}b_{11} & 0 & b_{13} \\ 0 & b_{22} & b_{23} \\ 0 & 0 & b_{33}\end{array}\right] \epsilon$ $\mathfrak{R}^{3 \times 3}, b_{11}=R T / V_{A}, b_{13}=-\left(R T / V_{A}\right) 2 K_{r} A_{c}, b_{22}=R T / V_{C}$, $b_{23}=-\left(R T / V_{C}\right) K_{r} A_{c}, b_{33}=\left(R T / V_{C}\right) 2 K_{r} A_{c}, x=\left[x_{1}, x_{2}\right.$, $\left.x_{3}\right]^{T}, u=\left[u_{1}, u_{2}, u_{3}\right]^{T}, q(x, u)=N\left(E^{o}+(R T / 2 F)\right.$ $\left.\ln \left\{x_{1}\left(x_{2} / P_{\text {std }}\right)^{1 / 2} / x_{3}\right\}\right)-N C \ln \left(\left(u_{3}+i_{n}\right) / i_{0}\right)-N r u_{3}-N m e^{n u_{3}}-$ $R_{l} u_{3}$.

Remark 1. The dynamic model is proposed by [1]. Notwithstanding, the PEM fuel cell with an external load is proposed in this study.

\section{Optimal Control Applied to PEM Fuel Cell}

In this section, the optimal control of the PEM fuel cell is designed.

Define the reference model as follows:

$$
\dot{x}_{d}=A x_{d}
$$

where $x_{d}=\left[x_{d, 1}, x_{d, 2}, x_{d, 3}\right]^{T}$ is the desired reference and $A$ is defined in (10). Subtracting (11) from (10), the closed-loop system is obtained as follows:

$$
\dot{\tilde{x}}=A \tilde{x}+B u=f(\tilde{x}, u),
$$

where $\tilde{x}=x-x_{d}$ is the tracking error and $u, A$, and $B$ are defined in (10).

The following theorem presents the optimal control applied to the PEM fuel cell.
Theorem 2. Consider the PEM fuel cell (10). Therefore, there exists an optimal controller to follow a desired behavior given as follows:

$$
u=-P^{-1}\left[\left(\frac{\partial A \tilde{x}}{\partial u}\right)^{T} S \tilde{x}+B^{T} S \tilde{x}\right]
$$

where $\partial A \tilde{x} / \partial u=\left[\begin{array}{lll}\partial a_{11} & \partial a_{12} & \partial a_{13} \\ \partial a_{21} & \partial a_{22} & \partial a_{23} \\ \partial a_{31} & \partial a_{32} & \partial a_{33}\end{array}\right] \in \mathfrak{R}^{3 \times 3}, \partial a_{11}=\left(R T / V_{A}\right)$ $\left(-\tilde{x}_{1} / p_{\text {op }}\right), \partial a_{12}=0, \partial a_{13}=\left(R T / V_{A}\right)\left(2 K_{r} A_{c}\left(\tilde{x}_{1} / p_{\text {op }}\right)\right)$, $\partial a_{21}=0, \partial a_{22}=\left(R T / V_{C}\right)\left(-\tilde{x}_{2} / p_{\text {op }}\right), \partial a_{23}=\left(R T / V_{C}\right)$ $\left(K_{r} A_{c}\left(\tilde{x}_{2} / p_{\text {op }}\right)\right), \partial a_{31}=0, \partial a_{32}=\left(R T / V_{C}\right)\left(-\tilde{x}_{3} / p_{\text {op }}\right)$, $\partial a_{33}=\left(R T / V_{C}\right)\left(-2 K_{r} A_{c}\left(\tilde{x}_{3} / p_{\text {op }}\right)\right), P \in \mathfrak{R}^{3 \times 3}$ is a constant and positive definite matrix, $\widetilde{x}$ is the system tracking error defined in (12), $S=\operatorname{diag}\left(s_{i}\right) \in \mathfrak{R}^{3 \times 3}$ is a positive definite matrix, $s_{1}, s_{2}$, and $s_{3}$ are positive scalar varying with time parameters, and an adaptive equation is given as follows:

$$
\dot{S}=-S A-A^{T} S-Q+S B P^{-1} B^{T} S+S B P^{-1}\left(\frac{\partial A \tilde{x}}{\partial u}\right)^{T} S .
$$

Proof. According to the optimal control technique $[17,18]$, a quadratic performance index is defined as

$$
J=\frac{1}{2} H\left(x_{f}\right)+\frac{1}{2} \int_{t o}^{t f} g(x, u) d t,
$$

where $g(x, u)$ is the average function and $H\left(x_{f}\right)$ is a function of the final time. The Hamiltonian is defined as follows [17, 18]:

$$
h(x, u, \lambda)=g(x, u)+\lambda^{T} f(x, u),
$$

where $\lambda=\left[\lambda_{1}, \lambda_{2}, \lambda_{3}\right]^{T}$. The equations to obtain the optimal control with the Hamilton-Jacobi-Bellman method are as follows $[17,18]$ :

$$
\begin{gathered}
0=\frac{\partial h(x, u, \lambda)}{\partial u}, \\
\dot{\lambda}=-\frac{\partial h(x, u, \lambda)}{\partial x} .
\end{gathered}
$$

Define the following quadratic performance index for the Hamilton-Jacobi-Bellman of this system [17, 18]:

$$
J=\frac{1}{2}{\widetilde{x_{f}}}^{T} H \tilde{x_{f}}+\frac{1}{2} \int_{t o}^{t f}\left(\tilde{x}^{T} Q \tilde{x}+u^{T} P u\right) d t,
$$

where $0 \leq H \in \mathfrak{R}^{3 \times 3}, 0<Q \in \mathfrak{R}^{3 \times 3}, u$ is the system input defined in (10), and $\widetilde{x_{f}}$ is the final tracking error. Using (12) and (18), the Hamiltonian is

$$
h(\tilde{x}, u, \lambda)=\frac{1}{2} \tilde{x}^{T} Q \tilde{x}+u^{T} P u+\lambda^{T}[A \tilde{x}+B u],
$$

where $A$ and $B$ are defined in (10). Applying the first equation of (17) to the Hamiltonian (19), it gives the following optimal control function:

$$
u=-P^{-1}\left[\left(\frac{\partial A \tilde{x}}{\partial u}\right)^{T} \lambda+B^{T} \lambda\right]
$$


TABle 1: Parameters of a PEM fuel cell.

\begin{tabular}{lc}
\hline Parameter & Value \\
\hline$V_{A}$ & $6.495 \mathrm{~cm}^{2}$ \\
$A_{C}$ & $136.7 \mathrm{~cm}^{2}$ \\
$V_{C}$ & $12.96 \mathrm{~cm}^{2}$ \\
$N$ & 35 \\
$P_{\text {op }}$ & $101 \times 10^{3} \mathrm{~Pa}$ \\
$T$ & $353^{\circ} \mathrm{K}$ \\
$E^{o}$ & $1.3 \mathrm{~V}$ \\
$R$ & $8.3144 \mathrm{~J} / \mathrm{mol}^{\circ} \mathrm{K}$ \\
$F$ & $96485 \mathrm{C} / \mathrm{mol}$ \\
$P_{\text {std }}$ & $101325 \mathrm{~Pa}$ \\
\hline
\end{tabular}

where $\lambda$ is obtained by applying the second equation of (17) to the Hamiltonian (19) given as follows:

$$
\dot{\lambda}=-Q \tilde{x}-A^{T} \lambda \text {. }
$$

Define $\lambda$ as follows:

$$
\lambda=S \tilde{x} .
$$

Substituting (22) into (20), it gives the optimal control function (13). Substituting (22) and (13) into (21) and considering $\dot{\lambda}=\dot{S} \tilde{x}+S \dot{\tilde{x}}$ and (12), it gives the adaptive equation (14).

Remark 3. First, the process starts with the initial conditions of $\tilde{x}$ and $S$; the adaptive equation (14) is solved at a time to find $\dot{S}$; then, the optimal control function (13) is solved at a time to find $u$; later, the fuel cell dynamic model (10) is solved to find $\dot{x}$. Then, the process starts again. The above-described process is directly solved using the software Simulink of MATLAB. $t_{f}$ is free in the numerical simulations because it can take different values without the requirement to remake additional calculus.

\section{Simulations}

In this study, the dual proportional derivative control with nonlinear compensation of [19] called PD and the optimal control called Optimal are compared by two simulations. The objective is that the plant states reach a desired trajectory; that is, the states $x_{1}, x_{2}$, and $x_{3}$ of (10) should reach the desired trajectories $x_{d, 1}, x_{d, 2}$, and $x_{d, 3}$. The dual PD control is used because it yields good results for both continuous and noncontinuous set points [19].

The root mean square error (RMSE) is used for the controllers comparison; it is given as follows [13, 14, 20]:

$$
\operatorname{RMSE}=\left(\frac{1}{T} \int_{0}^{T} e^{2} d \tau\right)^{1 / 2}
$$

where $e^{2}=\tilde{x}_{1}^{2}+\tilde{x}_{2}^{2}+\tilde{x}_{3}^{2}$ is the tracking error and $e^{2}=u_{1}^{2}+$ $u_{2}^{2}+u_{3}^{2}$ is the control function. $[1,2]$.

The parameters of the PEM fuel cell are given in Table 1

The other parameters are $\alpha=0.58, i_{0}=1 \times 10^{-4} \mathrm{~mA} / \mathrm{cm}^{2}$, $i_{n}=1 \times 10^{-4} \mathrm{~mA} / \mathrm{cm}^{2}, r=3.85 \times 10^{-4} \mathrm{k} \Omega \mathrm{cm}^{2}, m=3 \times 10^{-6} \mathrm{~V}$, and $n=8 \times 10^{-3} \mathrm{~cm}^{2} / \mathrm{mA}$.

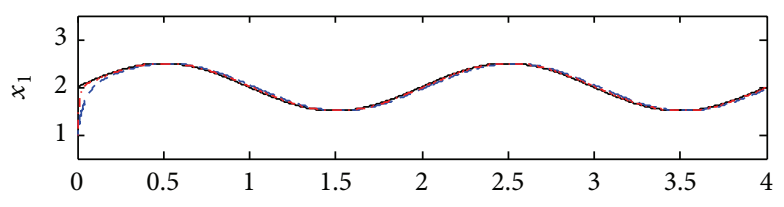

(a)

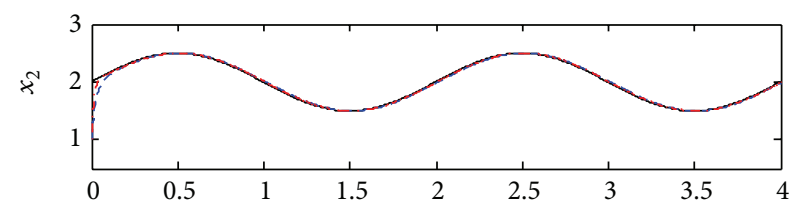

(b)

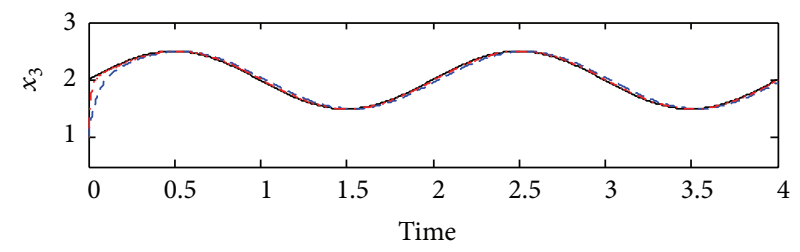

— Desired $\quad$-... Optimal
-- PD

(c)

FIGURE 2: Trajectory tracking of the states.

TABLE 2: Results for states and controls.

\begin{tabular}{lcc}
\hline Methods & RMSE for states & RMSE for controls \\
\hline Optimal & 0.0479 & 0.1395 \\
PD & 0.0932 & 0.2603 \\
\hline
\end{tabular}

TABLE 3: Results for states and controls.

\begin{tabular}{lcc}
\hline Methods & RMSE for states & RMSE for controls \\
\hline Optimal & 0.3103 & 2.3623 \\
PD & 0.4804 & 3.6732 \\
\hline
\end{tabular}

4.1. Example 1. The dynamic model for the PEM fuel cell is given by (10) with $N=35, R_{l}=1 \Omega$, states $x_{1}=p \mathrm{H}_{2}, x_{2}=$ $p \mathrm{O}_{2}$, and $x_{3}=p \mathrm{H}_{2} \mathrm{O}_{\mathrm{C}}$, inputs $u_{1}=\mathrm{H}_{2, \text { in }}, u_{2}=\mathrm{O}_{2 \text {,in }}$, and $u_{3}=$ $i$, and output $y=V, x_{1,0}=x_{2,0}=x_{3,0}=1$ Pa being the initial conditions for the states; $x_{d, 1}=x_{d, 2}=x_{d, 3}=2+0.5 \sin (\pi t) \mathrm{Pa}$ from $0 \mathrm{~s}$ to $4 \mathrm{~s}$ are the desired references.

The gains of the PD technique are $K_{p}=\operatorname{diag}\left(k_{p, j}\right), k_{p, 1}=$ $2 \times 10^{-1}, k_{p, 2}=2 \times 10^{-1}, k_{p, 3}=5, K_{d}=\operatorname{diag}\left(k_{d, j}\right), k_{d, 1}=$ $2 \times 10^{-3}, k_{d, 2}=4 \times 10^{-3}$, and $k_{p, 3}=5 \times 10^{-2}$.

Optimal is given by (13), (14) with parameters $P=$ $\operatorname{diag}(1) \in \mathfrak{R}^{3 \times 3}, Q=\operatorname{diag}(0.1) \in \mathfrak{R}^{3 \times 3}, S_{0}=\operatorname{diag}\left(s_{, j, o}\right) \in$ $\Re^{3 \times 3}, s_{1, o}=1.2 \times 10^{-3}, s_{2, o}=2.5 \times 10^{-3}$, and $s_{3, o}=2.5 ; S_{0}$ is the initial condition of $S$.

Figures 2, 3, and 4 show the trajectory tracking, control function, and output for Optimal and PD techniques applied to the PEM fuel cell, respectively. Table 2 shows the RMSE for the tracking error and control function.

From Figure 2, it can be seen that Optimal achieves better accuracy when compared with PD because the signals for 


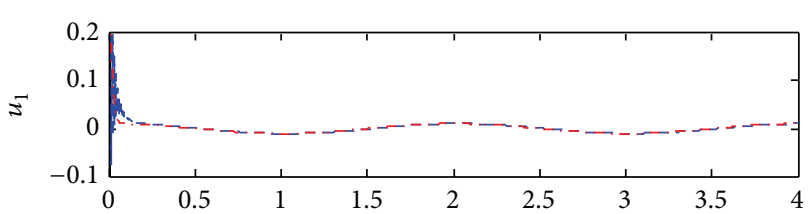

(a)

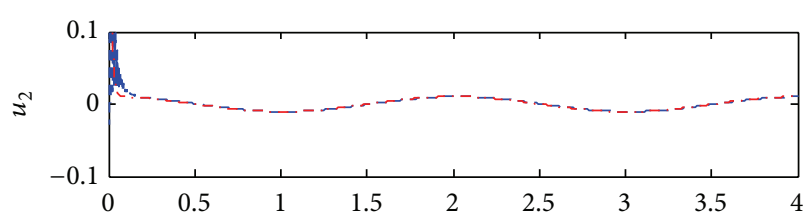

(b)

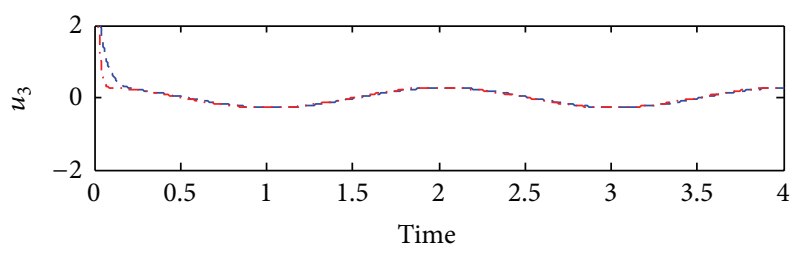

$---\mathrm{PD}$

(c)

Figure 3: Control functions.

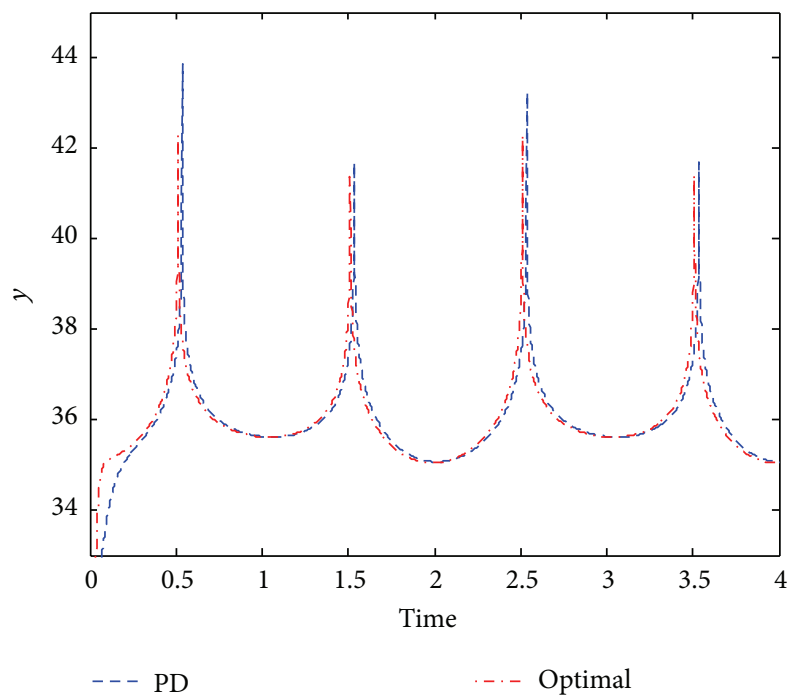

Figure 4: Outputs.

the first follow better the reference signals than for the other. From Figures 3 and 4, it can be seen that Optimal is better than PD because the first reaches smaller inputs than the other. From Table 2, it can be observed that Optimal achieves better accuracy when compared with PD because the RMSE is smaller for the first than for the other.

4.2. Example 2. The dynamic model for the PEM fuel cell is given by (10) with $N=35, R_{l}=1 \Omega$, states $x_{1}=p \mathrm{H}_{2}, x_{2}=$ $p \mathrm{O}_{2}$, and $x_{3}=p \mathrm{H}_{2} \mathrm{O}_{C}$, inputs $u_{1}=\mathrm{H}_{2, \text { in }}, u_{2}=\mathrm{O}_{2, \text { in }}$, and $u_{3}=i$, and output $y=V, x_{1,0}=x_{2,0}=x_{3,0}=2$ Pa being the

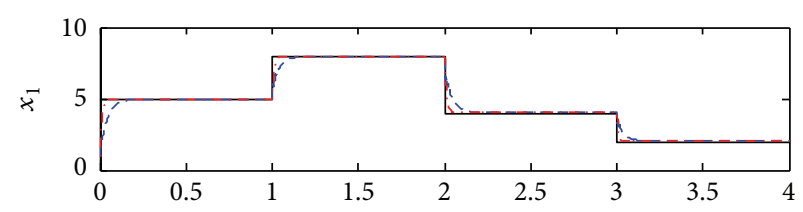

(a)

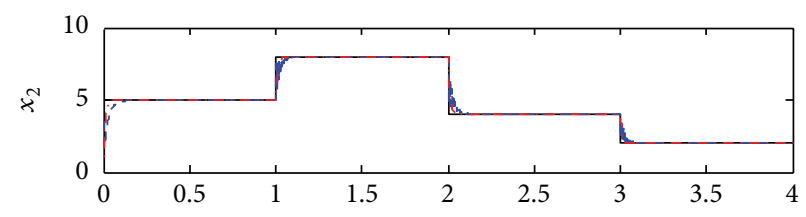

(b)

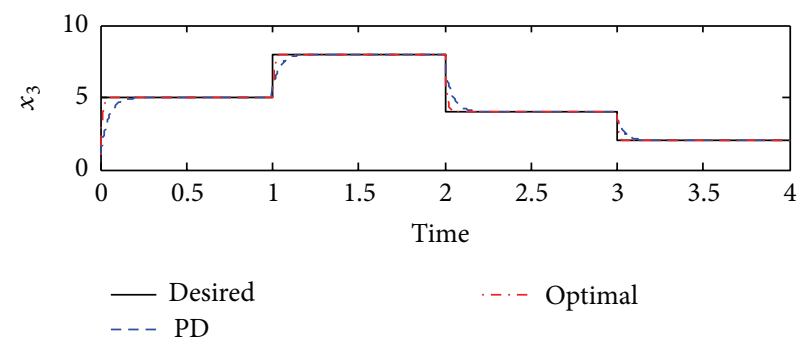

(c)

FIGURE 5: Trajectory tracking of the states.

initial conditions for the states; $x_{d, 1}=x_{d, 2}=x_{d, 3}=4 \mathrm{~Pa}$ from $0 \mathrm{~s}$ to $1 \mathrm{~s}, x_{d, 1}=x_{d, 2}=x_{d, 3}=5$ Pa from $1 \mathrm{~s}$ to $2 \mathrm{~s}, x_{d, 1}=x_{d, 2}=$ $x_{d, 3}=3 \mathrm{~Pa}$ from $2 \mathrm{~s}$ to $3 \mathrm{~s}$, and $x_{d, 1}=x_{d, 2}=x_{d, 3}=2 \mathrm{~Pa}$ from $3 \mathrm{~s}$ to $4 \mathrm{~s}$ are the desired references.

The gains of the PD technique are $K_{p}=\operatorname{diag}\left(k_{p, j}\right), k_{p, 1}=$ $2 \times 10^{-1}, k_{p, 2}=2 \times 10^{-1}, k_{p, 3}=5, K_{d}=\operatorname{diag}\left(k_{d, j}\right), k_{d, 1}=$ $2 \times 10^{-3}, k_{d, 2}=2 \times 10^{-3}$, and $k_{p, 3}=5 \times 10^{-2}$.

Optimal is given by (13), (14) with parameters $P=$ $\operatorname{diag}(1) \in \mathfrak{R}^{3 \times 3}, Q=\operatorname{diag}(0.1) \in \mathfrak{R}^{3 \times 3}, S_{0}=\operatorname{diag}\left(s_{, j, o}\right) \in$ $\Re^{3 \times 3}, s_{1, o}=1.2 \times 10^{-3}, s_{2, o}=2.5 \times 10^{-3}$, and $s_{3, o}=2.5 ; S_{0}$ is the initial condition of $S$.

Figures 5, 6, and 7 show the trajectory tracking, control function, and output for Optimal and PD techniques applied to the PEM fuel cell, respectively. Table 3 shows the RMSE for the tracking error and control function.

From Figure 5, it can be seen that Optimal achieves better accuracy when compared with PD because the signals for the first follow better the reference signals than for the other. From Figures 6 and 7, it can be seen that Optimal is better than PD because the first reaches smaller inputs than the other. From Table 3, it can be observed that Optimal achieves better accuracy when compared with PD because the RMSE is smaller for the first than for the other.

\section{Conclusion}

In this paper, the optimal controller applied to the PEM fuel cell was presented. The simulations showed that the optimal controller achieves better performance when compared with dual proportional-derivative technique for the trajectory 


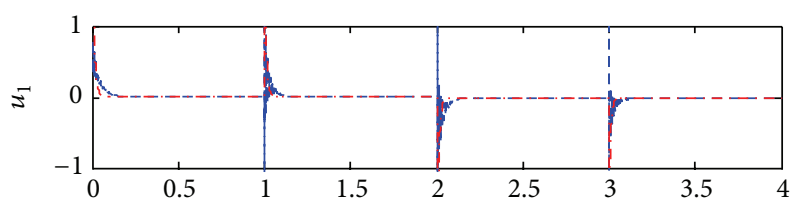

(a)

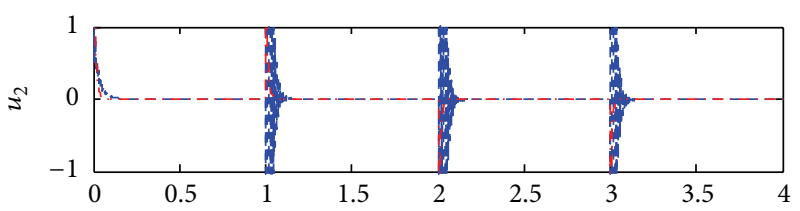

(b)

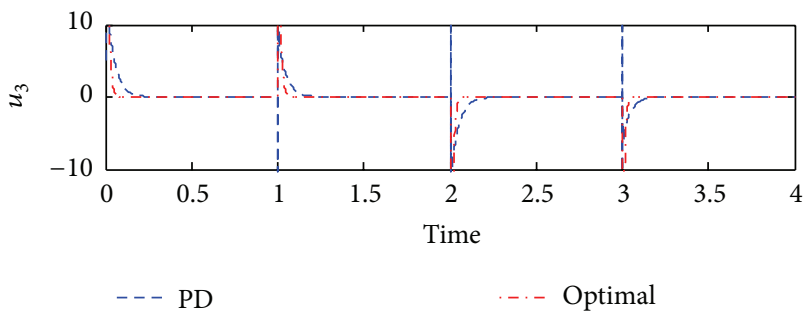

(c)

FIGURE 6: Control functions.

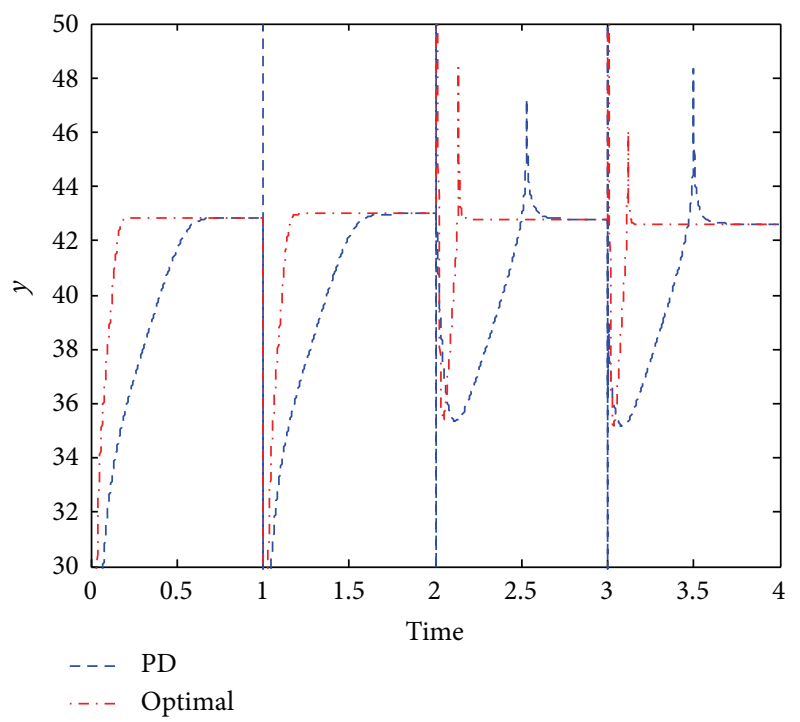

FIgURE 7: Outputs.

tracking and inputs minimization. As a future work, some parameters in the controller will be approximated using the intelligent systems [21-26].

\section{Conflict of Interests}

The authors declare no conflict of interests regarding all the aspects related to this paper.

\section{Acknowledgments}

The authors are grateful to the editor and to the reviewers for their valuable comments and insightful suggestions, which helped to improve this research significantly. The authors thank the Secretaría de Investigación y Posgrado, Comisión de Operación y Fomento de Actividades Académicas del IPN, and Consejo Nacional de Ciencia y Tecnología for their help in this research.

\section{References}

[1] W. K. Na, B. Gou, and B. Diong, "Nonlinear control of PEM fuel cells by exact linearization," IEEE Transactions on Industry Applications, vol. 43, no. 6, pp. 1426-1433, 2007.

[2] W. K. Na and B. Gou, "Feedback-linearization-based nonlinear control for PEM fuel cells," IEEE Transactions on Energy Conversion, vol. 23, no. 1, pp. 179-190, 2008.

[3] R. J. Talj, D. Hissel, R. Ortega, M. Becherif, and M. Hilairet, "Experimental validation of a PEM fuel-cell reduced-order model and a moto-compressor higher order sliding-mode control," IEEE Transactions on Industrial Electronics, vol. 57, no. 6, pp. 1906-1913, 2010.

[4] Y. Liu and H. Yu, "Fuzzy control of a pendulum-driven cart," in Proceedings of the International Conference on Modelling, Identification and Control (ICMIC '10), pp. 698-703, July 2010.

[5] Y. Liu and H. Yu, "Fuzzy control of an underactuated pendulum-driven cart system," International Journal of Advanced Mechatronic Systems, vol. 4, no. 5-6, pp. 260-268, 2012.

[6] S. Bi, M. Deng, L. Wang, and Y. Zhao, "Operator-based robust control for MIMO non-linear systems with uncertain hysteresis," International Journal of Advanced Mechatronic Systems, vol. 4, no. 5-6, pp. 212-220, 2012.

[7] M. Deng and N. Bu, "Robust control for nonlinear systems using passivity-based robust right coprime factorization," IEEE Transactions on Automatic Control, vol. 57, no. 10, pp. 25992604, 2012.

[8] M. Deng, S. Wen, and A. Inoue, "Sensorless anti-swing robust nonlinear control for travelling crane system using SVR with generalized gaussian function and robust right coprime factorization," Transactions of the Society of Instrument and Control Engineers, vol. 47, no. 9, pp. 366-373, 2011.

[9] A. Wang and M. Deng, "Operator-based robust nonlinear tracking control for a human multi-joint arm-like manipulator with unknown time-varying delays," Applied Mathematics \& Information Sciences, vol. 6, no. 3, pp. 459-468, 2012.

[10] S. Wen, M. Deng, S. Bi, and D. Wang, "Operator-based robust nonlinear control and its realization for a multi-tank process by using a distributed control system," Transactions of the Institute of Measurement and Control, vol. 34, no. 7, pp. 891-902, 2011.

[11] L. Jacic and D. Debeljkovic, "Bang-bangoptimal control for hidraulic systems," International Journal of Modelling and Simulation, 1984.

[12] V. Azhmyakov and R. Velazquez, "On a variational approach to optimization of hybrid mechanical systems," Mathematical Problems in Engineering, vol. 2010, Article ID 978736, 13 pages, 2010.

[13] J. J. Rubio, "Modified optimal control with a backpropagation network for robotic arms," IET Control Theory \& Applications, vol. 6, no. 14, pp. 2216-2225, 2012. 
[14] C. Torres, J. J. Rubio, C. Aguilar-Ibáñez, and J. H. Pérez-Cruz, "Stable optimal control applied to a cylindrical robotic arm," Neural Computing and Applications, vol. 24, no. 3, pp. 937-944, 2014.

[15] F. Loyola, "Ingenieria de celdas de combustible," in Hidrogeno: Introducción a la Energia Limpia, R. G. Gonzalez, E. Lopez, and B. Velazquez, Eds., chapter 6, 2009.

[16] W. Na and B. Gou, "The efficient and economic design of PEM fuel cell systems by multi-objective optimization," Journal of Power Sources, vol. 166, no. 2, pp. 411-418, 2007.

[17] I. Eronini, Umez-Eronini, System Dynamics and Control, Thomson Learning, 1998.

[18] F. L. Lewis and V. L. Syrmos, Optimal Control, 1995.

[19] S. Galvan-Colmenares, M. A. Moreno-Armendáriz, J. J. Rubio, F. Ortíz-Rodriguez, W. Yu, and C. F. Aguilar-Ibáñez, "Dual PD control regulation with nonlinear compensation for a ball and plate system," Mathematical Problems in Engineering. In press.

[20] J. J. Rubio, D. M. Vázquez, and D. Mújica-Vargas, "Acquisition system and approximation of brain signals," IET Science, Measurement \& Technology, vol. 7, no. 4, pp. 232-239, 2013.

[21] F. Bordignon and F. Gomide, "Uninorm based evolving neural networks and approximation capabilities," Neurocomputing, vol. 127, pp. 13-20, 2014.

[22] A. Buchachia, "Dynamic clustering," Evolving Systems, vol. 3, no. 3, pp. 133-134, 2012.

[23] A. Marques Silva, W. Caminhas, A. Lemos, and F. Gomide, "A fast learning algorithm for evolving neo-fuzzy neuron," Applied Soft Computing, vol. 14, part B, pp. 194-209, 2014.

[24] M. Pratama, S. G. Anavatti, P. P. Angelov, and E. Lughofer, "PANFIS: a novel incremental learning machine," IEEE Transactions on Neural Networks and Learning Systems, vol. 25, no. 1, pp. 55-68, 2014.

[25] M. Pratama, S. G. Anavatti, and E. Lughofer, "GENEFIS: towards an effective localist network," IEEE Transactions on Fuzzy Systems, vol. PP, no. 99, 2014.

[26] J. J. Rubio, "Evolving intelligent algorithms for the modelling of brain and eye signals," Applied Soft Computing, vol. 14, part B, pp. 259-268, 2014. 


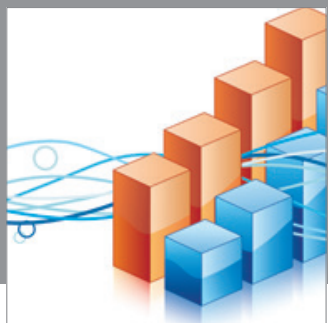

Advances in

Operations Research

mansans

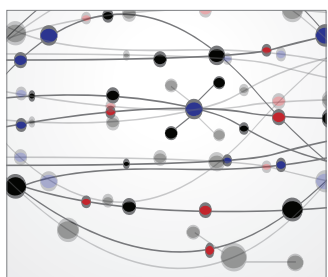

The Scientific World Journal
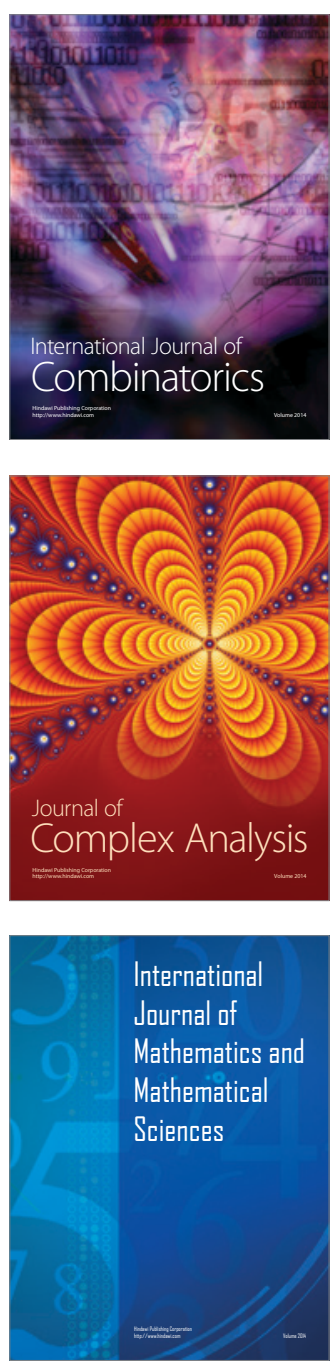
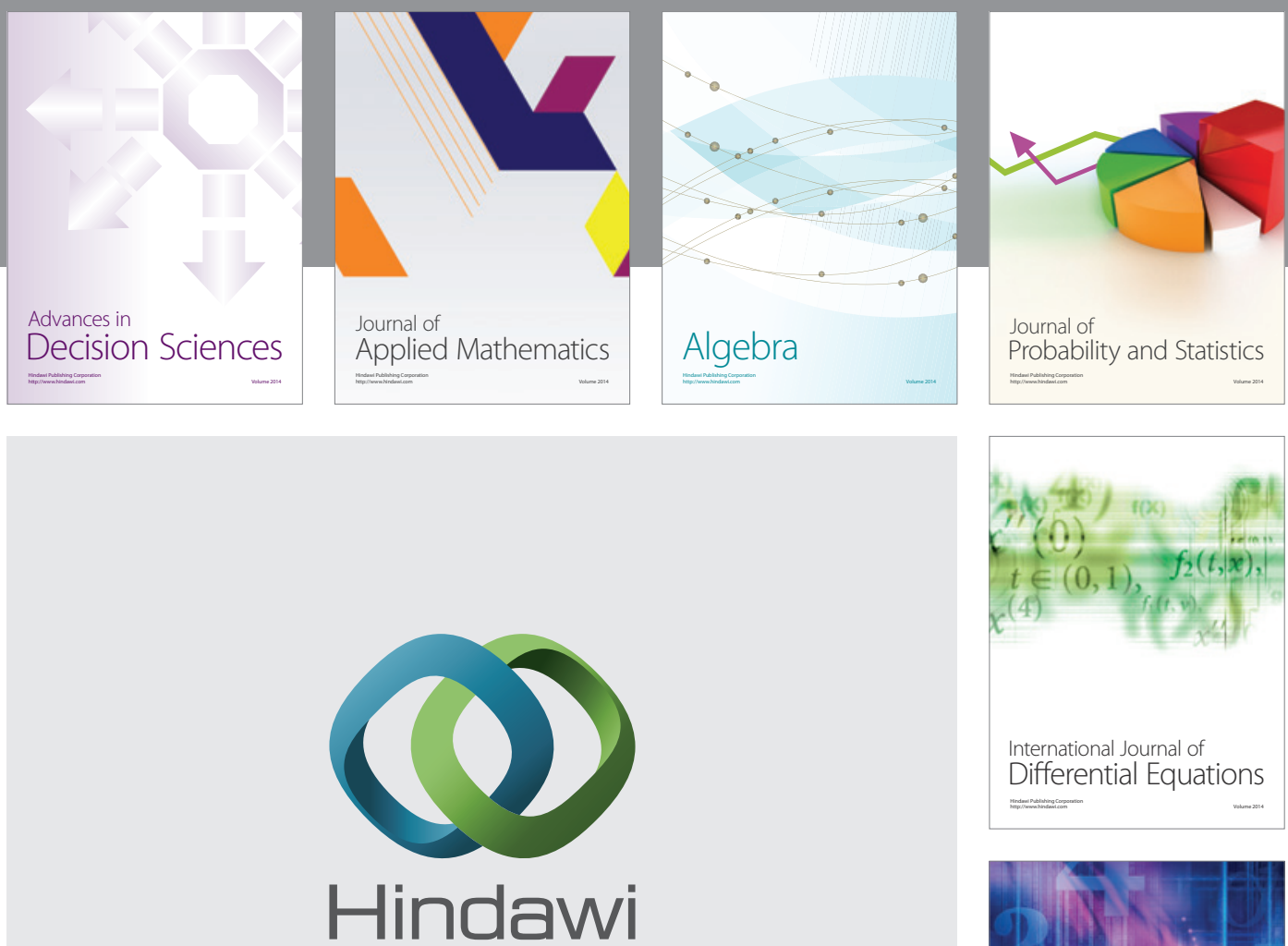

Submit your manuscripts at http://www.hindawi.com
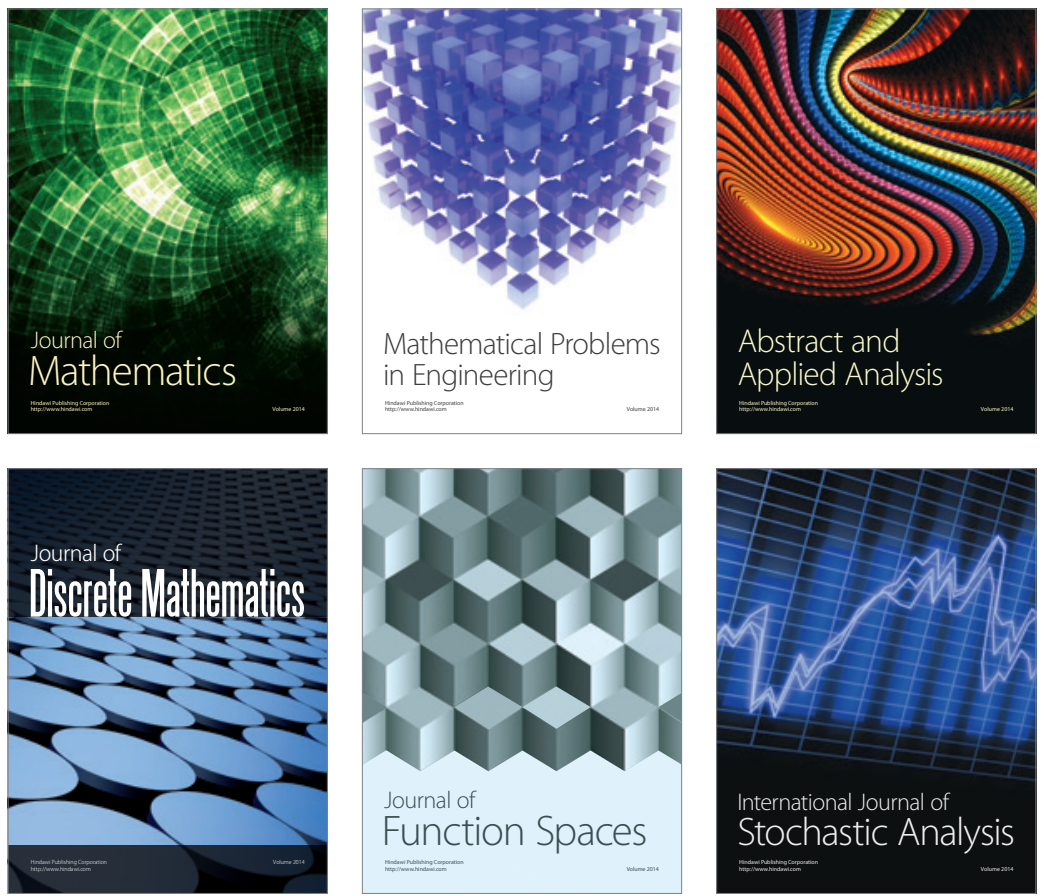

Journal of

Function Spaces

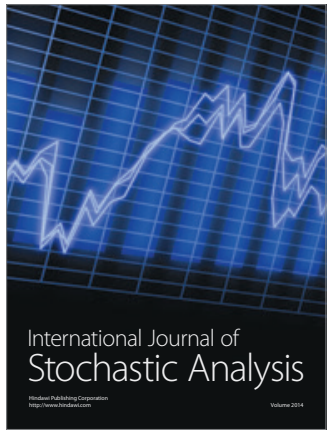

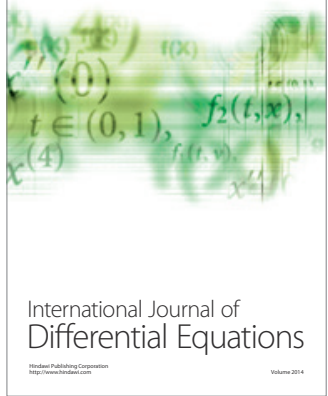
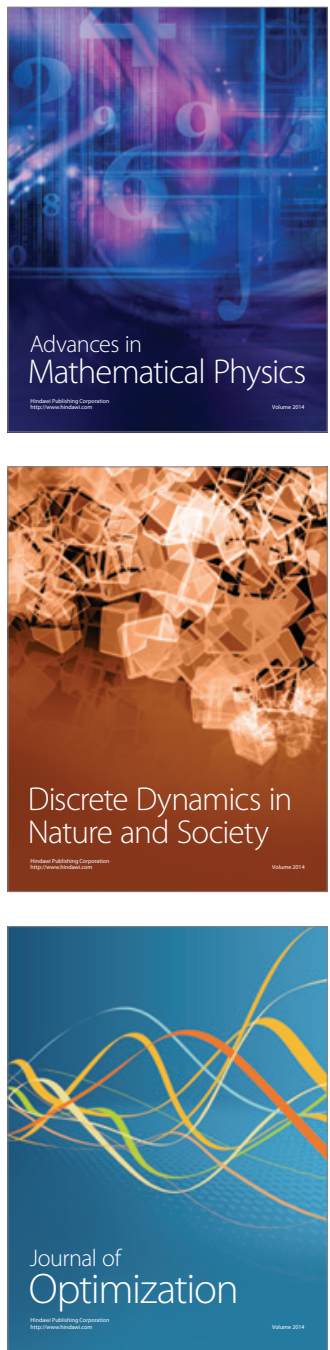